$\begin{array}{llllll}E & N & S & A & Y & O\end{array}$

\title{
RELACIONES DE GÉNERO \\ EN INVESTIGACIONES BASADAS \\ EN EXPERIENCIAS DE HISTORIA ORAL
}

Por: Olga Cabrera García

Artículo Recibido:
Artículo Aceptado:

\section{RESUMEN}

Este ensayo se propone analizar algunas cuestiones acerca de la perspectiva multidisciplinar en la metodología de la historia oral. Las investigaciones de historia oral tienen algunas características que le dan su especificidad pero, el artículo se concentra sobre dos de ellas: la entrevista y la construcción del documento oral. Se presentan algunas experiencias de ambas etapas de la investigación aunque el énfasis recae sobre el segundo aspecto. Se estudia la vida cotidiana así como la memoria, vinculadas al tiempo, con el propósito de comprender la historia oral.

Palabras Claves: Historia oral, vida cotidiana, memoria, relaciones de género

\section{ABSTRACT}

The main purpose of the article is to analyze some questions about the multidisciplinary perspective in the methodology of oral history. The oral history researches have some aspects but I will concentrate on two specifics aspects: the interview and the construction of the oral source. In this case I will present some experiences on both, but my emphasis will be on the second aspect: I study the quotidian live as well as the memory, linked to the time, in order to understand oral history.

\section{Key Words:}

\section{Introducción}

$\neg$ n la década del 70 comenzó un proceso de discusión en América Latina sobre las posibilidades de la Historia Oral en las investigaciones. Era una época en que algunos cuestionamientos a la historia desde los campos de 
la antropología primero y después de la filología y de la crítica literaria fueron hechos no apenas por su fragilidad científica sino también por su propuesta de alcanzar la verdad a partir de discursos y mediante narrativas maestras. La autoridad de las fuentes escritas comenzaba a caer por tierra aún cuando en la época los historiadores mostraban la eficiencia en el uso de la crítica de las fuentes mediante su confrontación con el contexto del cual procedían éstas.

Sin embargo, aún eran innumerables los cuestionamientos que los historiadores le atribuían no ya a otra visión sobre la historia sino al uso de las fuentes orales. Parecía que éstas integraban el oscuro y ambiguo mundo de la subjetividad en el paradigma diacrónico del otro polo, el negativo. Ese era el marco de la investigación en las ciencias humanas en general.

En los años 60 del siglo XX las obras de Gramsci penetraron en América Latina, creando expectativas en la forma de abordar las ciencias humanas en general. Lenin había publicado varios artículos sobre la cultura nacional (recopilados por Lenguas Extranjeras de la URSS en un volumen bajo el título de Cultura nacional), identificándola como dominante. Ésta, según su autor, era hegemónica y daba homogeneidad a toda la sociedad. El aporte gramsciano abrió una brecha en ese sólido y rígido constructo al plantear que las clases populares tenían un espacio de autonomía cultural. En el marxismo anterior a Gramsci, fue la influencia leninista, la que, durante mucho tiempo, había marcado la pauta en la interpretación sobre la actuación de los sectores o clases populares. Para Lenin, sólo una elite intelectual podía dirigir cualquier proceso de cambio. Con Gramsci, sin embargo, ganaron autonomía los espacios populares: había sí una cultura popular, obrera, campesina -según los posiciones que estuvieran bajo el foco de atención de los investigadores- y por lo tanto, era posible también estudiarla. Este fue el contexto que favoreció a la historia oral y la posibilidad de algunas felices asociaciones con otras ciencias sociales, la sociología, la antropología.

En la experiencia particular en México, el trabajo se adelantó desde las posiciones de historia oral con un equipo de antropólogos. Más tarde, en Brasil, los contactos más interesantes fueron con historiadores y sociólogos.

\section{Del Documento Escrito a la Experiencia de Historia Oral}

El tránsito de la autora en el campo de la historia oral está relacionado con la condición, experiencia y sensibilidad como mujer que permitieron problematizar el dominio jerárquico masculino en las relaciones de género entre obreros de la 
industria tabacalera. Venía trabajando en los archivos en la búsqueda de una historia obrera ejemplar a partir del convencimiento que tenía de su condición de vanguardia, y de poseer valores por los cuales debía regirse toda la sociedad. Era una época en que, muy jóvenes, se percibía la revolución cubana como un acontecimiento, y en esa perspectiva esta modalidad de investigación podía mostrar didácticamente y mediante un discurso canónico aquellos caminos que mostraban los "mejores", las figuras ejemplares, las "vanguardias".

Como se trataba de un período reciente de la historia cubana, de la cual había testimonios, frecuentemente algunos profesores orientaban hacia la realización de entrevistas pero la función de ésta era limitada a la confirmación de un criterio de interpretación ya preestablecido y, a veces, simplemente, de adorno, para mostrar que se había usado las entrevistas como una fuente más. Así se comenzó a visitar casas de tabaqueros para realizar entrevistas. Una cuestión valdría la pena resaltar. El proceso revolucionario en Cuba había impulsado a muchas jóvenes a incorporarse al mercado de trabajo y focalizaba negativamente la oposición de los hombres al trabajo femenino. Pero la liberación de la mujer, reducida a la expectativa de incorporación al mercado de trabajo, significó como ya ha sido revelado por algunas autoras (IBARRA, 2003) empeorar la situación de la mujer y mantener o profundizar algunos de los rasgos más onerosos del machismo cubano. La condición particular de joven madre casada que vivía las dificultades del día a día de la negociación de alguna libertad para la realización de su trabajo permitieron una mayor sensibilización para la comprensión de una situación de opresión de la mujer. Por eso, se pudo percibir la jerarquía entre los géneros durante estos encuentros con los tabaqueros. Evidencia que

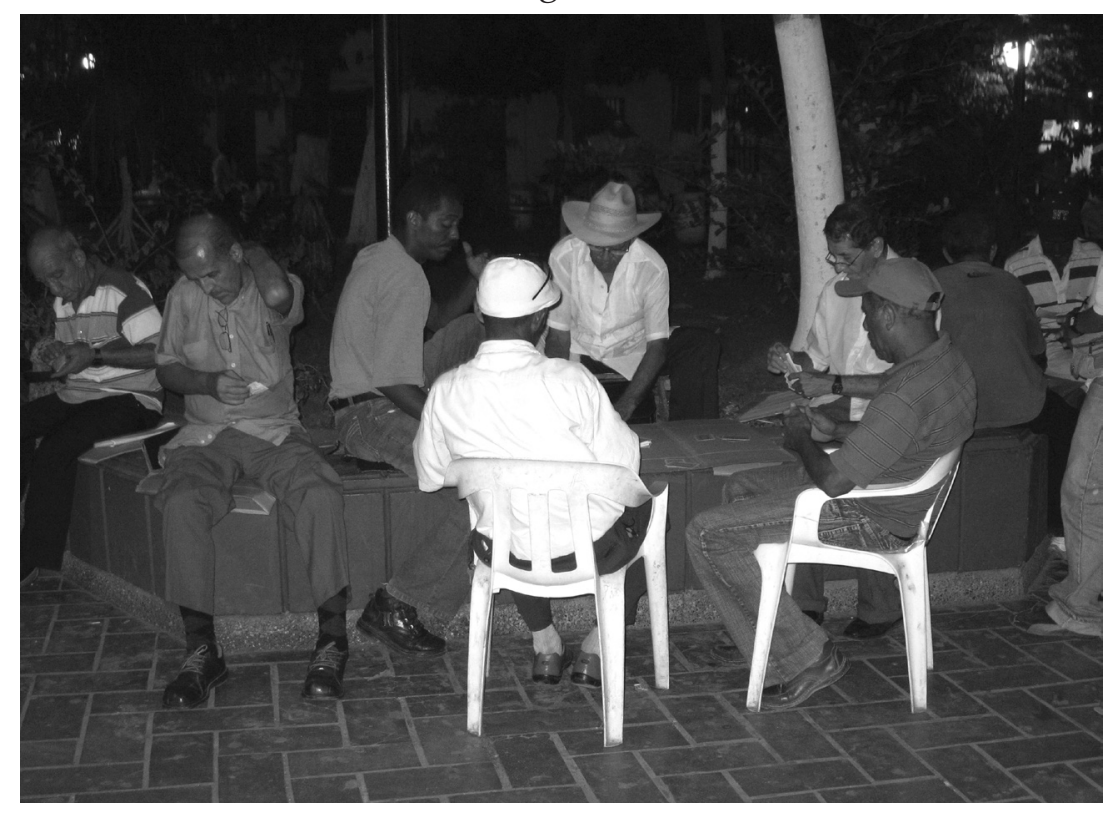
se reveló con una mayor crudeza cuando se le pidió a un tabaquero a quien se entrevistaba que llamara a la esposa, trabajadora como él en la misma fábrica, para que participara de la entrevista. La respuesta burlona y tajante delante de la propia esposa: "ella no sabe nada, mejor que se vaya a hacer el café" , hicieron comprender que algo fallaba en la comprensión de lo que era historia.

A los pocos, se fue desplazando 
el objeto de estudio de las "vanguardias" por las oscuras e invisibilizadas protagonistas de una historia para la cual ya no bastaba el documento escrito.

Naturalmente, que en la experiencia se comenzó a buscar a estas esposas y aprender de ellas como eran realmente las relaciones de género. No era que fueran sumisas, tal como a primera vista había parecido. Algunas cuestiones no las discutían porque consideraban que no tenía relevancia enfrentar al marido en todos los casos. Entre ellas, el hecho de participar o no en una entrevista. Así, cuando llegaba a otro horario en el cual el marido no estaba y podían conversar lo hacían y hasta ponían en tela de juicio algunos de sus testimonios. Pero también había espacios en que el marido no podía mediar. El salario tenía que ser entregado a la mujer y éste no pocas veces tenía que mentir para quedar con algo. Anteriormente, según revela la literatura, era el hombre quien administraba los gastos de la casa. En relación con los hijos no se podían adoptar medidas apenas por el hombre, ni aún en las peores situaciones económicas, a veces era la mujer la que asumía el control de la organización de éstos en una economía familiar donde todos tenían un papel que cumplir.

Sin duda, el uso de las entrevistas con mujeres esposas, hermanas, hijas fue cambiando el orden de relevancias en el abordaje como historiadora. Si antes buscaba al obrero y hombre en su papel de vanguardia de los cambios que se operaban en la historia cubana ahora los intereses iban por otra parte. Se reconocía la importancia de continuar en la historia y marcar los cambios, las transformaciones operadas por la acción de los hombres y mujeres pero ahora también se entendía que una dimensión de esos cambios podría ser estudiada en la vida cotidiana. Es decir, los cambios sociales debido a la emergencia de las mujeres a la vida pública, a la calle, al sindicato, podían también encontrar su explicación, indagando en aquellos resquicios ocultos y sin importancia de la vida cotidiana de mujeres y hombres.

Las evidencias del protagonismo femenino podían ser hurgadas en la vida privada y doméstica de las sencillas trabajadoras y "amas de casa". Se fue comprendiendo que por esos años, aún cuando la historia había producido un desplazamiento de su foco de interés hacía las historias de las clases obrera y campesina, continuaba operando el mismo mecanismo jerárquico de las relevancias. No se trataba de continuar abordando las ciencias humanas a partir de visiones dicotómicas, aunque éstas se dirigieran al polo de los oprimidos porque se les percibía aislados, siempre en un perpetúo enfrentamiento con las clases dominantes, dejando fuera los contactos, las relaciones, las negociaciones. Justamente esta fue la dimensión 
en que la historia oral aportaría sus mayores innovaciones. Por eso se entiende que no se trata simplemente de un método sino de una metodología, otro abordaje, aunque es importante resaltar que no se trata de una nueva historia, ella conlleva al reconocimiento del verdadero estatuto de la historia, como diría en alguna ocasión Luisa Passerini (1984).

La historia oral, por una parte, discutió el problema del lugar del investigador en su relación con el testimoniante, el narrador y de aquí derivaron importantes preocupaciones éticas que nunca se habían planteado los historiadores, ya que el ángel de la historia, al decir de Benjamín, continuaba con su vista estática al frente, al objetivo teleológico, sin ver las ruinas que se iban acumulando a sus pies.

Las distorsiones del pasado histórico respondían a la posición dominante del historiador ante unas fuentes manejadas a su antojo, ahora se trataba de establecer los principios éticos en las relaciones con el sujeto de la historia en el lugar de la enunciación. Son las experiencias de los protagonistas de la historia, las que van a servir para la interpretación. Y en esas experiencias del hombre y la mujer común otro elemento va a aparecer. Las fuentes escritas, seleccionadas para escribir una historia coherente y aceptable, eran utilizadas para el estudio de los grandes acontecimientos públicos pero con la historia oral van a tener visibilidad los pequeños hechos de una vida privada que fue relegada de la historia. El trabajo, la vida en el hogar, en la comunidad serán los contenidos de estas nuevas fuentes. Y esto significó dar una autonomía a los acontecimientos antes devaluados y reprimidos. El orden de relevancias de los comportamientos individuales y colectivos comenzó a ser instaurado. Y la vida cotidiana en las relaciones entre hombres y mujeres pasó a ser uno de los contenidos fundamentales de las fuentes orales.

\section{Relaciones de Género en la Lectura de Contextos}

En Cuba, durante los años 30 hay cambios radicales en relación a los comportamientos de las mujeres. En el movimiento estudiantil las mujeres participaron en las manifestaciones callejeras, firmaron manifiestos, en unos casos, como representantes exclusivamente femeninas, y en otros, compartiendo la representación en organizaciones mixtas.

En el movimiento obrero urbano salir a la calle, expresando su revuelta contra alguna situación, fue ejemplificado la primera vez en el año 1909 con las 
planchadoras de lavanderías. Algunas excepcionales mujeres compartieron asambleas, organizaciones obreras, como fue el caso de Emilia Rodríguez (CABRERA, 1999), pero estas actitudes se limitaron a algunas líderes anarquistas. Sólo en la década del 30 del siglo XX las mujeres de manera masiva comenzaron a ocupar las calles expresando su repulsa contra la dictadura de Gerardo Machado. La Policía no se encontraba preparada en aquellos momentos, desde la cultura de la represión, para como hombres enfrentar a mujeres, en la calle. De ahí que pensaron en un mecanismo inédito: el llamado a "prostitutas" para enfrentar a las mujeres profesionales, estudiantes y obreras. Pero, ¿qué se conocía sobre las mujeres de lugares más apartados del país, centrales azucareros, industrias localizadas próximas de las zonas rurales de mayor producción de caña de azúcar? ¿Qué ocurría en esos locales de cultura donde también arribaron mujeres aunque en menor número y se concentraron inmigrantes blancos procedentes de España y de la migración interna en Cuba y cubanos negros e inmigrantes negros procedentes del Caribe francés (haitianos), inglés y holandés? Algunas mujeres venían a los centrales sólo por algunos meses del año a ejercer la prostitución y terminando la zafra se marchaban.

En estos pequeños poblados comenzaron a aparecer algunos bares que no siempre fueron administrados por hombres sino que comenzó a ser más frecuente ver a las mujeres desempeñando estas actividades. Fueron los años inseguros que siguen a la crisis de 1920 y 1921 los que van a provocar una aparición cada vez más frecuente de la mujer en trabajos fuera de la casa. También en las ventas callejeras comienza a ser mucho más visible la mujer blanca. Ya no era sólo la negra o la mulata aunque ésta continuaba ejerciendo en mayor número las ventas callejeras. Pero ¿Cómo actuaron los resortes de estos cambios, cómo fue el proceso que otorgó a las mujeres un papel de decisión? ¿Dónde encontrar las respuestas a los cuestionamientos levantados frente a esa actividad inusitada de las mujeres en los sindicatos obreros y en las asociaciones? ¿Dónde buscar ese proceso de cambios, cómo orientar la búsqueda?

\section{La Interacción de la Diacronía, Vida Cotidiana y Memoria}

En la historia positivista había prevalecido el foco de estudio centrado en las elites, la conversión del espacio público en objeto de estudio privilegiado creó un nuevo orden de relevancias en el cual el pueblo y sus espacios fueron desvalorizados. De ese modo, la vida cotidiana fue reducida a vida privada, siendo invisibilizada. En la situación particular como historiadora oral, se formuló una hipótesis de trabajo, pensando en investigar sobre la vida cotidiana en los centrales azucareros 
cubanos para encontrar respuestas a la inusitada emergencia de las mujeres en los espacios públicos a partir de la década del 30 del siglo XX en Cuba.

La ausencia de fuentes escritas que informaran sobre los procesos que condujeron a esos cambios llevaron a transitar otros caminos y al abandono de los tradicionales de la historia. La historia oral se presentó como ejemplar para esta búsqueda y durante esa experiencia se pudo hasta problematizar algunas páginas de la historia oficial cubana. Interesante que en esa búsqueda de las relaciones de género en la vida cotidiana de los centrales azucareros, entrevistando a mujeres se logró cuestionar algunos acontecimientos narrados por la historia oficial. Una digresión sobre este asunto resulta necesaria. Transcurrían los años 70 en Cuba y la relación con la Unión Soviética parecía la única salida para la dirigencia cubana, en un contexto mundial caracterizado por la división del mundo en dos bloques, representando Estados Unidos el otro bloque de fuerza. En las Ciencias Sociales las obras que incidían en dar historicidad a los vínculos con la Unión Soviética eran muy bien recibidas. Fue así que comenzaron a ser publicados grandes volúmenes sobre los soviets en los centrales azucareros cubanos cuya historicidad la hacían remontar al período que siguió al derrumbe de la dictadura de Machado en el año 1933.

Esta investigación desde la historia oral no focalizó los acontecimientos, aunque no pocas veces éstos pueden ser re-evaluados desde este campo. El caso es que en las entrevistas de los hombres éstos relataban siempre la declaración del soviet en el central Mabay. Pero en ninguna de las narrativas de las mujeres fueron mencionados los soviets, aunque los acontecimientos de esos días eran recordados hasta en sus mínimos detalles. Ellas relataron que la gerencia se marchó del central sin pagar los salarios de varios meses, que se concentraron con sus hijos junto a las cadenas que eran utilizadas para limitar la entrada central. Que exigieron comida y que el sindicato decidió matar dos o tres bueyes de la propiedad del central, y distribuir la carne y el cuero en partes iguales para las familias. Relatan aún que hicieron la gran fiesta después de varios meses de penurias. Pero estos acontecimientos en la narración de los hombres no eran importantes, ellos referían otros: la proclamación del soviet, el izamiento de la bandera del sindicato (en realidad era la roja y negra anarquista), los mensajes cruzados con el secretario de Gobernación del Gobierno Provisional.

El cruzamiento de unas y otras entrevistas y las diferencias levantadas entre ellas, contribuyeron a realizar una nueva entrevista, entonces colectiva con los tres dirigentes sobrevivientes del "soviet" de Mabay. En ese momento, por 
excepción, se utilizó una pregunta directa: ¿Ud sabe lo que es soviet?, provocando las siguientes respuestas. Uno respondió "se lleva en el corazón", otro, "está en el diccionario" y el último "no sé". Profundizando sobre el por qué de esta historia confirmaron, sin ningún tipo de conflicto, todo lo contrario, sonrientes, que ellos crearon durante el XV congreso azucarero su historia primero que la de los dirigentes del central Hormiguero.

De esta experiencia lo más importante fue reconocer que las mujeres se detenían en los pequeños detalles pero también estaban menos sujetas al presente de la historia oficial. La memoria sufre un proceso de "acomodación" en el presente pero también es recordado aquello que marcó la vida de la persona en el pasado. Las mujeres, de hecho, revelaron estar muy poco influenciadas por la historia oficial de ese momento. La historia sobre el soviet se apoyaba también en la documentación del Partido Comunista que en 1933 esgrimía como tácticas, "clase contra clase" y proclamaba "todo el poder a los soviets", acuerdos de la III Internacional stalinista que aparecen en todos los manifiestos de los Partidos Comunistas de América Latina en ese período.

La historia cubana, a partir de los años 70 al tratar de privilegiar el protagonismo del Partido Comunista en el pasado cubano, daba como cierto que esas consignas se habían transformados en experiencias en algunos lugares. El argumento que lo justificaba estaba en la visión de continuidad de la historia hacía un objetivo final que era el socialismo. Si Cuba era el primer país "socialista" de América Latina, ciertamente eso respondió a la presencia en el pasado de manifestaciones y fuerzas que apuntaban para este objetivo. Así, en 1975, durante el XV Congreso Azucarero los testimonios de la presencia de los primeros soviets cubanos fueron muy bien recibidos, resultando homenajeados como primer soviet el de Mabay, donde se realizaron las entrevistas apenas unos años más tarde y el segundo, el de Hormiguero.

Como se ha intentado mostrar, varios problemas revela la construcción del documento oral, procedimiento que se corresponde con el proceso de validación de

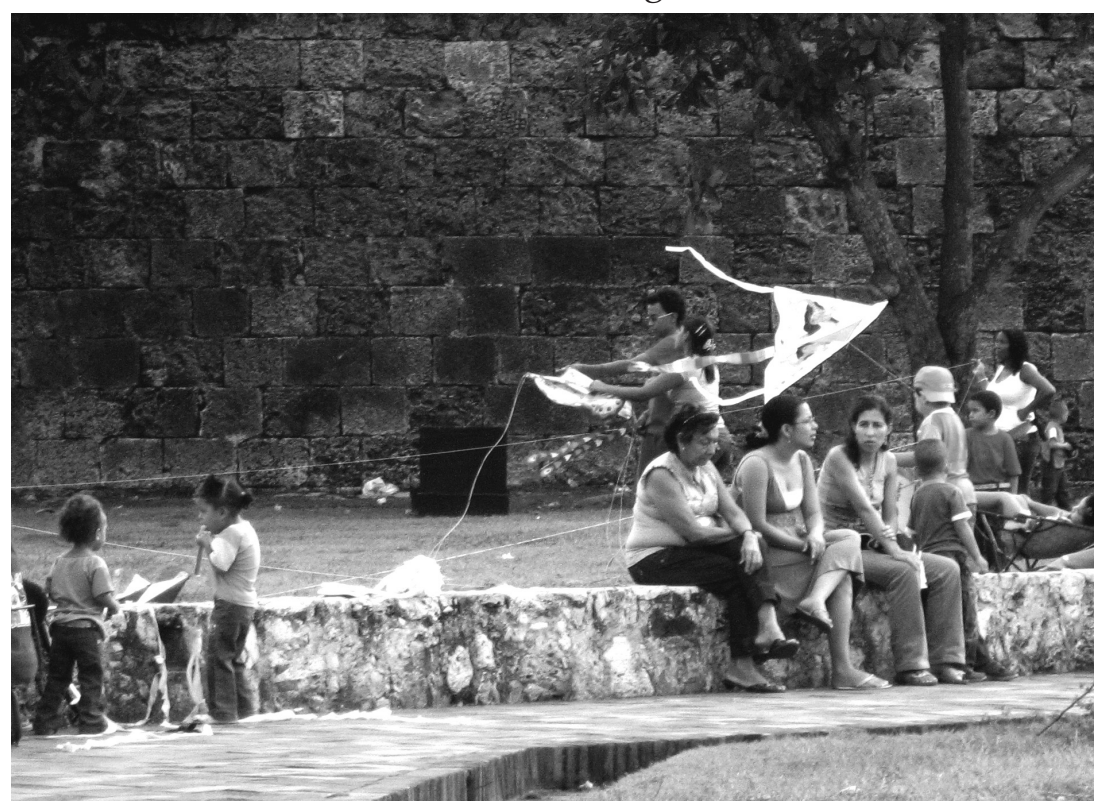


las fuentes orales. El primero que, el día a día en los espacios del trabajo, de las relaciones en lugares de encuentros, espacios deportivos, parques, bares, en las bodegas localizadas en los campos donde se escuchaba la única radio existente, los prostíbulos y por último el hogar, son imprescindibles para encontrar las claves de las transformaciones que se van operando en la sociedad. Hay que distinguir cuales espacios no son frecuentados por la mujer, aunque algunos como los bares en los centrales comienzan a ser invadidos por mujeres inmigrantes. El caso de la prostitución es diferente o la ejercían mujeres inmigrantes o cubanas procedentes de otros lugares que se marchaban al término de la zafra.

En los espacios comunes donde transcurrían las relaciones de género, los significados, los sentidos tienen una construcción cultural diferente, no sólo por tratarse de encuentros de inmigrantes y nacionales, también como se pudo comprobar entre las mujeres y los hombres. En las narrativas de mujeres es posible analizar una menor influencia de la retórica oficial. Otro aspecto interesante es la presencia de una mayor visión colectiva aunque limitada a la familia, observada entre las mujeres. El tiempo está marcado por las necesidades de "mis hijos", "mi casa", las enfermedades, los nacimientos, la primera personas del singular es de muy escaso uso. En los hombres predomina la primera o la tercera persona del singular en los relatos, y la primera persona del plural siempre emerge en las narrativas con una mayor presencia de la retórica procedente del discurso oficial.

\section{BIBLIOGRAFIA}

CABRERA, Olga (1989) "El mundo de la despalilladora cubana". En: Historia y fuente oral. No 1, v. 1. Barcelona. págs. 151- 159.

CABRERA, Olga. (2007). "Uma entrevista en análise", En Revista de Pesquisa Qualitativa. Sao Paulo.

CABRERA, Olga. (1999). Emilia Rodríguez. Ediciones Orto. Madrid.

IBARRA, Isabel. (2003). "Mujeres en Cuba (1980-1998)".XX Revista Brasileira do Caribe. Goiania, v. IV , no. 8, /Junho. Rio de Janeiro.

PASSERINI, Luisa, THOMPSON, Paul. (1997). Our conmun history. Pluto. London: 1984. 
THOMSON, Alistair. (1997). "Recompondo a memoria: Questöes sobre a relaçäo entre a História Oral e as memórias". Projeto História. No 15, Abril. Säo Paulo.

THOMPSON, Paul. (1992). La voz del pasado. Paz e Terra. Río de Janeiro

\section{BIOGRAFIA}

Profesora asociada de la Pós Graduación de Historia de la Universidad de Brasilia (Brasil). Directora del Centro de Estudios del Caribe en Brasil (CECAB) y los simposios bianuales que el Centro ha gestado desde hace nueve años. Directora de la Revista Brasileira do Caribe. Profesora invitada en el doctorado en Ciencias de la Educación (RUDECOLOMBIA) de la Universidad de Cartagena. Ha publicado los libros "Los que viven por sus manos" (1986), "Mella una historia de las relaciones mexicocubanas" (2002) y "Emilia Rodríguez" (1999). e-mail: olgacabrera@uol.com.br 